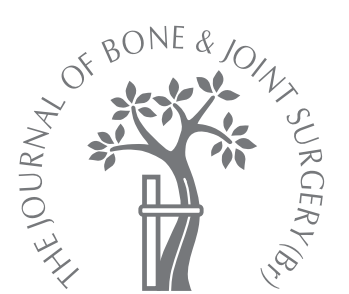

J. Aderinto,

J. F. Keating

From Royal

Infirmary,

Edinburgh, Scotland

\section{Intramedullary nailing of fractures of the tibia in diabetics}

I J. Aderinto, FRCS, MD, MSc, Orthopaedic Specialist Registrar

I. J. Keating, FRCSEd(Orth), Consultant Orthopaedic

Surgeon

Department of Orthopaedic

Trauma

Royal Infirmary, Little France, Old Dalkeith Road, Edinburgh EH16 4SU, UK.

Correspondence should be sent to Mr J. Aderinto; e-mail: joeaderinto@hotmail.com

C2008 British Editorial Society of Bone and Joint Surgery doi:10.1302/0301-620X.90B5. $19854 \$ 2.00$

$J$ Bone Joint Surg $[\mathrm{Br}]$ 2008;90-B:638-42.

Received 22 June 2007;

Accepted after revision 9

January 2008

We reviewed 27 diabetic patients who sustained a tibial fracture treated with a reamed intramedullary nail and compared them with a control group who did not have diabetes. There were 23 closed fractures and four were open. Union was delayed until after six months in 12 of the $23(52 \%)$ diabetic patients with closed fractures and ten of the $23(43 \%)$ control patients $(p=0.768)$. In two patients with diabetes $(9 \%)$, closed tibial fractures failed to unite and required exchange nailing, whereas all closed fractures in the control group healed without further surgery $(p=0.489)$. In both the diabetic and control groups with closed fractures two patients $(\mathbf{9} \%)$ developed superficial infections. There were two $(\mathbf{9} \%)$ deep infections in diabetic patients with closed fractures, but none in the control group $(p=$ 0.489).

Overall, there was no significant difference in the rate of complications between the diabetic patients and the control group, but there was a tendency for more severe infections in patients with diabetes.

It has been estimated that in 2000, worldwide, there were 171 million people with diabetes, and this is projected to increase to 366 million by $2030 .^{1}$ In the United Kingdom the prevalence of diabetes in 2007 was $3.66 \%$. Factors that have contributed to the increase in prevalence of diabetes include obesity and reduced physical activity. ${ }^{2}$ Glucose-induced microvascular and macrovascular disease results in damage to end organs, the sequelae of which include retinopathy, arteriopathy and poor wound healing. ${ }^{3,4}$ Peripheral neuropathy increases the risk of ulceration of the foot and of Charcot joints. ${ }^{5,6}$

Previous studies have shown an increase in complications in diabetic patients undergoing orthopaedic procedures (Table I), ${ }^{7-14}$ but there is limited information in relation to the outcome following the operative treatment of diaphyseal fractures of the tibia. This study evaluated the outcome of fractures of the tibia treated with reamed intramedullary nails in diabetic patients.

\section{Patients and Methods}

We identified 31 patients with diabetes who had sustained a unilateral diaphyseal fracture of the tibia and were treated with a reamed intramedullary nail at our institution between 1996 and 2006. Four were lost to follow-up less than one month after injury and were excluded from the study. The complications, including deep and superficial infection and compartment syndrome, and the time to union were recorded in the remaining 27 fractures, of which four were open and 23 were closed. The mean follow-up was for 13 months (3 to 40).

In closed fractures, a single prophylactic intravenous dose of $1.5 \mathrm{~g}$ cefuroxime was administered pre-operatively. Patients with open fractures were started on intravenous antibiotics at the time of admission, prior to wound debridement and stabilisation of the fracture treatment continued until soft-tissue coverage of the wound was achieved.

Continuous monitoring of the pressure of the anterior compartment of the lower leg was carried out using a slit catheter in all patients on the day of admission. ${ }^{15}$ Their blood pressure was also measured, and the difference between the diastolic blood pressure and compartment pressure ( $\Delta$ pressure) was calculated at selected intervals. A $\Delta$ pressure below $30 \mathrm{mmHg}$ was considered to be an indication for fasciotomy. ${ }^{16}$

A fracture was judged to be united when there was radiological evidence of bridging of three of four cortices on standard anteroposterior and lateral views, as assessed by the senior author (JFK). Fractures that required further surgery to achieve healing were designated nonunions. 
Table I. Summary of the literature relating to the treatment of fractures in diabetic patients

\begin{tabular}{|c|c|c|}
\hline Study & Topic & Outcome \\
\hline Borg et $\mathrm{al}^{7}$ & Percutaneous plating of distal tibial fractures & $\begin{array}{l}21 \text { closed tibial fractures treated with percutaneous plating } \\
\text { Two deep infections with nonunion, both in diabetic patients }\end{array}$ \\
\hline Jones et $\mathrm{al}^{8}$ & Ankle fractures & Complication rate: comorbid diabetics $47 \%$; non-diabetics $14 \%, p<0.05$ \\
\hline McCormack and Leith ${ }^{9}$ & Ankle fractures & Complication rate: diabetics $42.3 \%$; non-diabetics $0 \%$ \\
\hline Höiness et al ${ }^{10}$ & Ankle fractures & $\begin{array}{l}\text { Three of nine diabetic patients had soft-tissue complications but diabetes } \\
\text { not a significant risk factor, } p=0.415\end{array}$ \\
\hline Flynn et al ${ }^{11}$ & Ankle fractures & Infective complications: diabetics $32 \%$; non-diabetics $8 \%$ \\
\hline Blotter et al ${ }^{12}$ & Ankle fractures & Complication rate: diabetics $43 \%$; non-diabetics $15.5 \%$ \\
\hline Ganesh et al ${ }^{13}$ & Ankle fractures & $\begin{array}{l}\text { Increased post-operative complications in diabetic patients compared } \\
\text { with non-diabetic patients } p<0.001\end{array}$ \\
\hline Simpson et $\mathrm{al}^{14}$ & Lumbar spine posterior decompression & Wound complications: diabetics $34 \%$; non-diabetics $0 \%$ \\
\hline
\end{tabular}

Table II. Details of diabetic and control patients with fractures of the tibia

\begin{tabular}{|c|c|c|c|c|}
\hline & \multicolumn{2}{|l|}{ Diabetic } & \multicolumn{2}{|l|}{ Control } \\
\hline & Closed (n = 23) & Open (n = 4) & Closed (n = 23) & Open (n = 4) \\
\hline Men (\%) & $17(74)$ & $3(75)$ & $17(74)$ & $3(75)$ \\
\hline $\begin{array}{l}\text { Mean age in years } \\
\text { (range) }\end{array}$ & 54.48 (17 to 94$)$ & $\begin{array}{l}42(17 \text { to } \\
70)\end{array}$ & 54.65 (16 to 89$)$ & 43.5 ( 21 to 71 ) \\
\hline \multicolumn{5}{|l|}{ Fracture site } \\
\hline Proximal third & 3 & 0 & 0 & 0 \\
\hline Middle third & 1 & 1 & 6 & 0 \\
\hline Distal third & 19 & 3 & 17 & 4 \\
\hline $\begin{array}{l}\text { Mean time to surgery } \\
\text { in days (range) }\end{array}$ & 2.74 (0 to 26$)$ & $<1$ & 1.61 (0 to 8 ) & $<1$ \\
\hline
\end{tabular}

Information relating to peripheral neuropathy and the vascular status of the lower legs was obtained from the medical records. Only two patients were recorded as having diabetic comorbidity, which comprised a peripheral neuropathy and retinopathy in one patient and occlusive arterial disease with absent dorsalis pedis and posterior tibial pulses in another.

A total of 14 patients with closed fractures had noninsulin dependent diabetes, and the remaining nine were insulin dependent. All four patients with open fractures had insulin-dependent diabetes. On admission, the mean white cell count was $10.2 \times 10^{9} / 1$ (5.8 to 24$)$ and the mean neutrophil count was $7.6 \times 10^{9} / 1$ (3.11 to 22.03 ). In 20 patients the fracture was caused by a low-energy fall, and in five by high-energy trauma secondary to a motor vehicle accident (MVA). In a further two patients the fractures were sustained while playing rugby and during an assault, respectively. Of the four open fractures two were classified as grade 1 , one as grade $3 \mathrm{a}$, and one as grade $3 \mathrm{~b}$, according to the revised Gustilo and Anderson classification. ${ }^{17,18}$
Infection was considered to be superficial in the presence of cellulitis without evidence of wound drainage or a subcutaneous collection of infected material, and deep when discharge of purulent material from bone required removal of the intramedullary nail or bony debridement.

A control group of 27 non-diabetic patients who had sustained fractures of the tibia during the study period and who were treated by intramedullary fixation were individually matched for age, gender and fracture type (Table II). In the control group, the four open fractures comprised two grade 1 , one grade $3 a$ and one grade $3 b$.

Statistical analysis. Fisher's exact test was used to compare rates of infection and of fasciotomy, and the time to union between open and closed fractures. Student's $t$-test was used for age comparisons between the groups.

\section{Results}

Healing of the fractures. The times to union for closed and open fractures are shown in Table III. In the closed injuries healing was delayed until after six months in 12 of 23 $(52 \%)$ diabetic patients, compared with ten of $23(43 \%)$ 
Table III. Time to union

\begin{tabular}{|c|c|c|c|c|}
\hline \multirow[b]{2}{*}{ Time to union } & \multicolumn{4}{|c|}{ Months } \\
\hline & $<6$ & 6 to 8 & 8 to 12 & $>12$ \\
\hline \multicolumn{5}{|c|}{ Diabetic patients } \\
\hline Closed & 11 & 9 & 2 & 1 \\
\hline Open $^{*}$ & & 2 & & 1 \\
\hline \multicolumn{5}{|l|}{ Control } \\
\hline Closed & 13 & 6 & 4 & 0 \\
\hline Open & 1 & 2 & 1 & \\
\hline
\end{tabular}

in the non-diabetic group $(\mathrm{p}=0.768)$. Exchange nailing was performed for nonunion in two of $23(9 \%)$ closed fractures in the diabetic patients and in one of four $(25 \%)$ open injuries. One of the closed fractures was complicated by deep infection after the primary nailing and required exchange nailing for nonunion. There were no nonunions in the control group, all fractures uniting without further surgery.

The details of diabetic patients who developed infection are shown in Table IV. Infection occurred in four of the 23 $(17 \%)$ diabetic patients with closed fractures (Table V), two superficial and two deep. One of the two with persistent deep infection was treated with exchange nailing, and the other had the nail removed after the fracture had united. Infection occurred in two of the four diabetic patients with open fractures, both of which were deep. One of these patients had a below-knee amputation four months after intramedullary nailing. Deep infection developed, which was followed by distal migration of the intramedullary nail, resulting in septic arthritis of the ankle.

In the control group of 23 closed fractures there were two $(9 \%)$ superficial but no deep infections. There was no significant difference in the rate of deep infection between diabetic and control patients with closed fractures $(\mathrm{p}=0.489)$. Superficial wound infections occurred in three of four open fractures in the control group, all of which were treated successfully with antibiotics. There were no deep infections in this group. There was no significant difference in the infection rate between diabetic and control patients with open fractures $(\mathrm{p}=1.000)$.

Fasciotomies. Fasciotomies for impending compartment syndrome in closed fractures were carried out in five of 23 $(22 \%)$ patients with diabetes and in four of the $23(17 \%)$ in the control group (Table V). Fasciotomy was needed in two of four open fractures in diabetic patients and in none of the four open fractures in the control group $(p=0.429)$. The mean age of diabetic patients undergoing fasciotomy was 49 years ( 26 to 75 ), compared with 54 years (17 to 94) in patients who did not require fasciotomy $(\mathrm{p}=0.612)$.

Complications. Considering the combined rates of infection, fasciotomy and surgical intervention to achieve union in closed fractures, 11 complications occurred in nine dia- betic patients $(39 \%)$ and six in five patients $(21 \%)$ in the control group ( $\mathrm{p}=0.337)$.

In patients with closed fractures there was no significant difference in the rate of infection, union delayed for more than six months, or fasciotomy between insulin-dependent and non-insulin dependent diabetic patients. The only complication in the two patients with diabetic comorbidity was a fasciotomy for a compartment syndrome which was carried out in a patient with absent peripheral pulses.

\section{Discussion}

Diabetic patients had higher rates of deep infection, delayed union and nonunion, but because of the limited number of patients in this study these differences did not reach statistical significance.

The rates of fasciotomy for the diabetic patients and controls were similar, at $22 \%$ and $17 \%$ respectively, but were higher than described in previous studies. ${ }^{19-21}$ In contrast to the control patients, in whom all fractures united without further surgery, nonunion occurred in two diabetic patients with closed fractures and one with an open fracture. However, one of the closed fractures that developed nonunion was complicated by deep infection after the primary nailing, which may have been a contributing factor. When considering all infections in closed and open fractures, there was no notable difference in the rate of infection between diabetic and control patients. However, in the control group infections in the open and closed fractures were superficial and were treated successfully with antibiotics alone, whereas in the diabetic patients half of the infections in closed fractures were deep, and in the open fractures all were deep. All deep infections required further surgery, comprising either removal or exchange of the nail.

The size of the sample comprising 27 patients is relatively small, which is a weakness of this study. However, the prevalence of diabetes in the United Kingdom is $3.66 \%$, and assuming that diabetic patients have the same risk of fracture of the tibia as the general population, one would expect 27 diabetic patients per 737 patients with such fractures. Based on the rates of infection observed in this study, the sample size required to detect a difference in rates of infection between control and diabetic patients would be 255 for a level of significance set at 0.05 and a power of 0.8 . Based on a $3.66 \%$ population prevalence of diabetes, more than 6900 tibial fractures would be required to obtain this number of eligible patients.

In diabetic patients the combination of vascular compromise and peripheral neuropathy increases the risk of complications. In addition, at the cellular level, diabetic patients are prone to deficiencies in the production of growth factor, angiogenic response and macrophage function, which result in impairment of wound healing and an increased risk of skin ulceration. ${ }^{22,23}$

Although information relating to the outcome following surgical stabilisation of fractures of the shaft of the tibia in diabetic patients is limited, several studies have described 
Table IV. Clinical details of diabetic patients with infective complications

\begin{tabular}{|c|c|c|c|c|c|c|c|c|}
\hline Patient & $\begin{array}{l}\text { Age } \\
\text { (yrs) }\end{array}$ & Diabetes type* & $\begin{array}{l}\text { Fracture grade (Gustilo } \\
\text { and Anderson) })^{17,18}\end{array}$ & $\begin{array}{l}\text { Infection } \\
\text { characteristics }\end{array}$ & Organism & $\begin{array}{l}\text { Surgical intervention } \\
\text { for infection }\end{array}$ & $\begin{array}{l}\text { Additional } \\
\text { operations }\end{array}$ & $\begin{array}{l}\text { Union } \\
\text { (mths) }\end{array}$ \\
\hline 1 & 58 & NIDDM & Closed & Deep infection & None isolated & Removal of nail & 2 & 6 to 8 \\
\hline 2 & 35 & IDDM & Closed & Deep infection & $\begin{array}{l}\text { Coagulase-negative } \\
\text { staphylococcus }\end{array}$ & $\begin{array}{l}\text { Three exchange } \\
\text { nailings }\end{array}$ & 3 & 8 to 12 \\
\hline 3 & 43 & IDDM & Grade 1 & Deep infection & Pseudomonas & $\begin{array}{l}\text { One exchange } \\
\text { nailing followed by } \\
\text { bone grafting and } \\
\text { removal of nail for } \\
\text { persistent infection }\end{array}$ & 5 & $>12$ \\
\hline 4 & 37 & IDDM & Grade 3b & Deep infection & Pseudomonas & Removal of nail & 2 & Amputation \\
\hline 5 & 58 & IDDM & Closed & $\begin{array}{l}\text { Superficial } \\
\text { wound infection }\end{array}$ & $\begin{array}{l}\text { Methicillin-resistant } \\
\text { Staphylococcus } \\
\text { aureus }\end{array}$ & No & 0 & $<6$ \\
\hline 6 & 47 & NIDDM & Closed & Cellulitis & None isolated & No & 0 & $<6$ \\
\hline
\end{tabular}

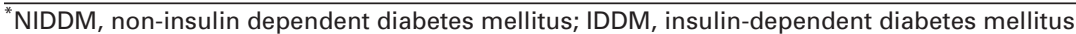

Table V. Complications after intramedullary nailing of closed tibial fractures

\begin{tabular}{lccc}
\hline & Diabetics $(\mathbf{n}=\mathbf{2 3})$ & Control $\mathbf{n}=\mathbf{2 3})$ & p-value* \\
\hline Infection & 2 & 2 & \\
$\quad$ Superficial & 2 & 0 & 0.489 \\
Deep & 4 & 2 & 0.665 \\
$\quad$ & & & \\
Total & 5 & 4 & 1.000 \\
Fasciotomy & 12 & 10 & 0.768 \\
$\quad$ Union delayed $>$ 6 mths & 2 & 0 & 0.489 \\
$\quad$ Exchange nailing for nonunion
\end{tabular}

* Fisher's exact test

increased rates of complication in diabetic patients undergoing fixation of ankle fractures..$^{8,9,11-13}$ Such studies have shown increased rates of infection, malunion, loss of fixation and an increased need for additional surgery. ${ }^{9,12,13}$ Diabetic comorbidity, such as peripheral neuropathy and microvascular disease, and the diabetes itself, may be the cause of the increased risk of complications. ${ }^{8}$ Jones et $\mathrm{al}^{8}$ compared the outcome of ankle fractures in diabetic patients treated with surgical fixation with a control group and found that overall there was no difference in the rate of complications, but there was an increase in complications in the subgroup of patients with diabetes-related comorbidity.

In our study only two patients had diabetic comorbidity, and so it was not possible to establish whether the presence of peripheral neuropathy or vascular insufficiency was related to any of the outcome measures.

Following trauma to the lower limb it is important to establish whether there is evidence of peripheral neuropathy or vascular compromise. Vascularity can be assessed clinically by examining for pedal pulses and checking the capillary refill. Objective methods of assessment include the ankle brachial pressure index ${ }^{24}$ which has a normal range from 0.9 to 1.3 , although this may be falsely high in diabetic patients owing to calcification of the walls of the arteries. ${ }^{25}$ In such cases toe pressures can be measured using Doppler ultrasound or photoplethysmography, and the toe- brachial index pressure calculated. The toe-brachial pressure index has been shown to be more accurate than the ankle brachial pressure index for assessment of lower limb blood supply in the presence of arterial calcification. ${ }^{24}$

Peripheral neuropathy results in impairment of motor, sensory and autonomic function which can lead to muscle atrophy and loss of protective sensation. Autonomic sympathetic dysfunction results in vasodilation in the skin, with reduced sweating producing increased warmth and dryness of the skin that increases the risk of breakdown. Clinical assessment of light touch, pinprick and vibration sensation can provide useful information about the extent of somatosensory impairment. Recognised techniques for assessment of peripheral neuropathy include the use of a $10 \mathrm{~g}$ Semmes-Weinstein monofilament which is pressed against the plantar skin to assess pressure perception. ${ }^{26}$ Alternatively, a pressure-specific sensory device can be used to assess somatosensory function. ${ }^{27}$

We have shown a trend towards an increase in complications in diabetic patients after intramedullary nailing of tibial fractures. Although there was no significant difference in the infection rate between diabetic and control patients, there was a tendency for the diabetics to suffer with more severe infections which required further surgery. Thorough pre- and post-operative clinical assessment of the lower limbs is required to establish whether there is evidence of peripheral neuropathy or vascular compromise, 
which are recognised risk factors for poor wound healing and skin breakdown. A careful surgical technique is mandatory so that compromise of soft-tissue viability is reduced to a minimum. Patients with diabetes should be advised of the potential increased risks at the time of consent for surgery.

\section{Supplementary Material}

$\because$ A further opinion by Professor A. Nather is available with the electronic version of this article on our website at www.jbjs.org.uk

No benefits in any form have been received or will be received from a commercial party related directly or indirectly to the subject of this article.

\section{References}

1. Wild S, Roglic G, Green A, Sicree R, King H. Global prevalence of diabetes: estimates for the year 2000 and projections for 2030. Diabetes Care 2004;27:1047-53.

2. Wild SH, Byrne CD. ABC of obesity: risk factors for diabetes and coronary heart disease. BMJ 2006:333:1009-11.

3. Gardiner TA, Archer DB, Curtis TM, Stitt AW. Arteriolar involvement in the microvascular lesions of diabetic retinopathy: implications for pathogenesis. Microcirculation 2007:14:25-38.

4. Greenhalgh DG. Wound healing and diabetes mellitus. Clin Plast Surg 2003;30:3745.

5. Armstrong DG, Lavery LA, Holtz-Neiderer K, et al. Variability in activity may precede diabetic foot ulceration. Diabetes Care 2004;27:1980-4.

6. Simon SR, Tejwani SG, Wilson DL, Santner TJ, Denniston NL. Arthrodesis as an early alternative to nonoperative management of Charcot arthropathy of the diabetic foot. J Bone Joint Surg [Am]2000;82-A:939-50.

7. Borg T, Larsson S, Lindsjö U. Percutaneous plating of distal tibial fractures: preliminary results in 21 patients. Injury 2004;35:608-14.

8. Jones KB, Maiers-Yelden KA, Marsh JL, et al. Ankle fractures in patients with diabetes mellitus. J Bone Joint Surg [Br] 2005;87-B:489-95.

9. McCormack RG, Leith JM. Ankle fractures in diabetics: complications of surgical management. J Bone Joint Surg [Br] 1998;80-B:689-92.

10. Höiness $\mathbf{P}$, Engebretsen $\mathbf{L}$, Strömsöe K. Soft tissue problems in ankle fractures treated surgically: a prospective study of 154 consecutive closed ankle fractures. Injury 2003;34:928-31.
11. Flynn JM, Rodriguez-del Rio F, Pizá PA. Closed ankle fractures in the diabetic patient. Foot Ankle Int 2000;21:311-19.

12. Blotter RH, Connolly E, Wasan A, Chapman MW. Acute complications in the operative treatment of isolated ankle fractures in patients with diabetes mellitus. Foot Ankle Int 1999;20:687-94.

13. Ganesh SP, Pietrobon R, Cecilio WA, et al. The impact of diabetes on patient outcomes after ankle fracture. J Bone Joint Surg [Am] 2005;87-A:1712-18.

14. Simpson JM, Silveri CP, Balderston RA, Simeone FA, An HS. The results of operations on the lumbar spine in patients who have diabetes mellitus. J Bone Joint Surg [Am] 1993;75-A:1823-9.

15. Rorabeck CH, Castle GS, Hardie R, Logan J. Compartmental pressure measurements: an experimental investigation using the slit catheter. J Trauma 1981;21:446-9.

16. McQueen MM, Court-Brown CM. Compartment monitoring in tibial fractures: the pressure threshold for decompression. J Bone Joint Surg [Br] 1996;78-B:99-104.

17. Gustilo RB, Anderson JT. Prevention of infection in the treatment of one thousand and twenty-five open fractures of long bones: retrospective and prospective analyses. J Bone Joint Surg [Am] 1976;58-A:453-8.

18. Gustilo RB, Mendoza RM, Williams DN. Problems in the management of type Ill (severe) open fractures: a new classification of type III open fractures. J Trauma 1984;24:742-6.

19. McQueen MM, Christie J, Court-Brown CM. Compartment pressures after intramedullary nailing of the tibia. J Bone Joint Surg [Br] 1990;72-B:395-7.

20. Alho A, Ekeland A, Strømsøe K, Follerås G, Thoresen BO. Locked intramedullary nailing for displaced tibial shaft fractures. J Bone Joint Surg [Br] 1990;72-B:805-9.

21. Finkemeier CG, Schmidt AH, Kyle RF, Templeman DC, Varecka TF. A prospective, randomized study of intramedullary nails inserted with and without reaming for the treatment of open and closed fractures of the tibial shaft. J Orthop Trauma 2000; 14:187-93.

22. Brem H, Sheehan P, Rosenberg HJ, Schneider JS, Boulton AJ. Evidence-based protocol for diabetic foot ulcers. Plast Reconstr Surg 2006;117:193-209.

23. Brem H, Tomic-Canic M. Cellular and molecular basis of wound healing in diabetes. J Clin Invest 2007;117:1219-22.

24. Brooks B, Dean R, Patel S, et al. TBI or not TBI: that is the question: is it better to measure toe pressure than ankle pressure in diabetic patients? Diabet Med 2001;18:528-32

25. Khan NA, Rahim SA, Anand SS, Simel DL, Panju A. Does the clinical examination predict lower extremity peripheral arterial disease? JAMA 2006;295:536-46.

26. Singh N, Armstrong DG, Lipsky BA. Preventing foot ulcers in patients with diabetes. JAMA 2005;293:217-28.

27. Tassler PL, Dellon AL. Correlation of measurements of pressure perception using the pressure-specified sensory device with electrodiagnostic testing. J Occup Environ Med 1995;37:862-6. 